\title{
Scatterometry for land hydrology science and its applications
}

\author{
P. K. Gupta*, R. Pradhan, R. P. Singh and A. Misra \\ Earth, Ocean, Atmosphere, Planetary Sciences and Applications Area (EPSA), Space Applications Centre, ISRO, Ahmedabad 380 015, India
}

\begin{abstract}
This study reports the potential of SCATSAT-1 scatterometer data for catchment-scale hydrological applications related with river water level estimation and flood detection. New approaches have been developed for estimation of river water levels and detection of surface flooding using Oceansat-II scatterometer (OSCAT) and SCATSAT-1 scatterometer-based highresolution backscatter and brightness temperature (BT) datasets respectively. Ku-band sigma-0 and BT data, Shuttle Radar Topography Mission Digital Elevation Model and observed hydrometric data have been used in this study. Catchments of gauging sites and their influencing areas were delineated using the topography, wetness conditions and land-cover variations. OSCAT time series of scatterometer image reconstruction data were used to develop model function between basin water index and ground-observed river-stage datasets. Subsequently, inverting these functions on SCATSAT-1 observations, river water levels for 2017 were estimated at different gauging sites. A study on the magnitude of each flooding event in terms of intensity, duration and extent of area affected was also carried out using the scatterometerbased BT data analysis. The study demonstrated that high temporal resolution scatterometer data has the potential to fill the gap of coarser temporal resolution altimeters (10-35 days) for river heights and Synthetic Aperture Radar Data (7-25 days) for surface flooding with the advantage of capturing extreme events.
\end{abstract}

Keywords: Backscattering coefficient, brightness temperature, river water level, scatterometers, soil wetness.

\section{Introduction}

REMOTE sensing instruments working in the microwave region of the electromagnetic spectrum can be operated day and night, and are less affected by atmospheric conditions. This has prompted much research and development in the field of microwave remote sensing. Although scatterometers have been mainly used in ocean applications (wind velocity and wind direction) ${ }^{1}$, they have some unique hydrological applications over land surface. Scat-

\footnotetext{
*For correspondence. (e-mail: pkgupta@sac.isro.gov.in)
}

terometer measures geophysical variables related to the earth's water cycle, including precipitation rate, cloud water, water vapour, soil moisture, sea level, ice concentration and snow water equivalent ${ }^{2-5}$. Emission and reflectivity of land surfaces are affected by soil properties such as dielectric constant due to change in soil moisture, soil roughness, etc. ${ }^{6,7}$. Over land surfaces, backscatter is related to surface roughness and dielectric properties, whereas brightness temperature (BT) is related to emissivity and temperature ${ }^{8}$.

A remote sensing-based measurement strategy for rivers is emerging with radar scatterometers which are designed to determine the normalized radar cross-section (sigma-0) with high accuracy. Measurements are done at relatively coarse spatial resolution of $25-50 \mathrm{~km}$, since they average out pulses received over a wide area to accurately measure the return amplitude 9 . While this does not allow detailed analyses of surfaces, it does have the advantage of covering a larger portion of the earth on a more frequent basis (1-2 days) compared to altimeters. This frequent coverage is desirable for monitoring catchment-scale hydrological processes to assess the regional distribution of water. Soil has a relatively low dielectric constant (DC) of 3-7, whereas water has a high DC of 80 in the microwave region. Thus, changes in the moisture content causes a substantial change in DC of soil, which in turn causes a detectable change in backscatter. Moreover, backscatter typically increases with increase in soil wetness, until it gets completely saturated ${ }^{10}$. Observations of river floodplain inundation areas, soil wetness, water levels and flow variability from orbital sensors have the potential to directly measure the run-off component of the earth's hydrologic cycle ${ }^{11-13}$.

Measurement of temporal variations in water level of rivers is necessary due to various reasons such as: (a) lack of river gauging stations in remote areas, (b) for initialization, parameterization and calibration of hydrological models, and (c) for use in flood forecasting and monitoring systems. Routine monitoring of river water level is critical for disaster risk management and hydrological research. Scipal et al. ${ }^{14}$ used ERS scatterometerderived soil moisture products to develop the soil moisture-run-off relationships for the Zambezi river in southeastern Africa using multi-year data. This study serves as one of the first demonstrations that there is hydrologically relevant information in coarse-resolution 
satellite data. De Jeu et al. ${ }^{15}$ used microwave radiometer (AMSR-E) and scatterometer (ERS) data to generate global soil moisture patterns. Hirpa et al. ${ }^{16}$ used passive microwave information to study the upstream and downstream relationships for river discharge forecasting. Basin-level rainfall and associated soil wetness influence the fluctuations in river water levels through surface runoff. This forms the basis of our study, in which we formulate the relationship between OSCAT-derived basin water index (BWI) and ground-observed river stage data, and use these model functions to retrieve water-level information from SCATSAT-1.

When the soil surface is completely inundated by water, the emissivity decreases causing reduction in BT measured in microwave frequencies. The reduction of BT in horizontal polarization is greater compared to that in vertical polarization ${ }^{10}$. This property of water can be utilized to detect surface inundation. Many studies have demonstrated the potential of using high-resolution synthetic aperture radar (SAR) data to map the extent of surface flooding ${ }^{12,13,17,18}$. SAR sensors have excellent spatial resolution (of the order of a few metres), but lack the necessary temporal resolution to efficiently monitor flood events. Scatterometers have the capability to cover large swaths and provide 1-2 day repetivity with coarser spatial resolution. This provides a unique opportunity to continuously monitor flood events at catchment scale, and obtain valuable information about the affected regions and the duration of flooding. Brakenridge et al. ${ }^{19}$ used SeaWinds scatterometer on QuikSCAT to develop a flood detection algorithm using the backscatter polarization ratio. SCATSAT-1 provides $\mathrm{BT}$ data at $13.6 \mathrm{GHz}(\mathrm{Ku}-$ band) in horizontal and vertical polarizations, and we have used this data to detect inundated pixels.

The overall aim of this study was to assess the potential of Ku-band scatterometer-observed high-resolution backscattering coefficients (using scatterometer image reconstruction (SIR) technique) and BT for estimating river water levels and detection of surface flooding conditions. Algorithms were formulated for retrieval of river stage information using BWI and detection of surface flooding conditions using BT data.

\section{Study area}

The mainland of India, excluding Andaman and Nicobar, and Lakshadweep islands, was taken as the study area for surface flooding. Gauging sites covering some of the major river basins of India such as the Brahmaputra, Godavari, Mahi, Tapi, Narmada, Mahanadi, Subarnarekha, Brahmini and Baitrani were taken for river water level retrieval (Figure 1). India receives over $80 \%$ of annual rainfall in four monsoon months of June to September. Pre-monsoon and post-monsoon rainfall is a common phenomenon experienced each year during May and October respectively, and affects the antecedent soil wetness conditions which are eventually responsible for the quantification of river discharge and water levels through the process of run-off.

\section{Data used}

SCATSAT-1 is a continuity mission for Oceansat-2 scatterometer (OSCAT) for ocean weather forecasting, cyclone detection and tracking, etc. The satellite carries a $\mathrm{Ku}$-band $(13.516 \mathrm{GHz})$ scatterometer; it performs scanning in a conical fashion in $H H$ and $V V$ polarizations and allows to develop high-resolution datasets due to high overlapping areas.

The following satellite-derived high-resolution datasets were used in this study for the estimation of river water levels and surface inundation mapping. In situ river water levels were used for the development of model functions and their validation.

- Ku-band (OSCAT) SIR sigma-0 $(4 \times 4 \mathrm{~km})$ product for Southeast Asia (SAs) with alternate-day resolution, downloaded from the Brigham Young University (BYU) website for 2010-13.

- Ku-band SCATSAT-1 L4 India daily sigma-0 SIR product $(2 \times 2 \mathrm{~km})$ for December 2016-December 2017.

- SCATSAT-1 L4 India daily BT ( $H$ and $V$ pol) descending orbit product $(2 \times 2 \mathrm{~km})$ for 2017 .

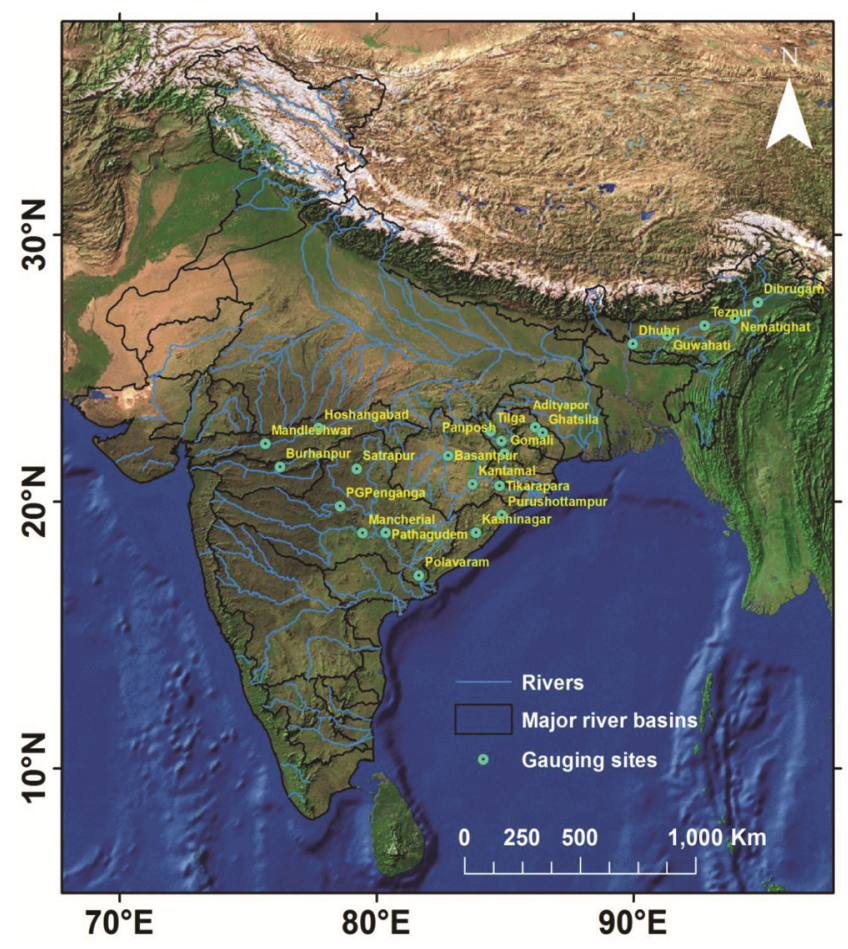

Figure 1. Study area showing gauging sites in different basins of India. 
- Shuttle Radar Topography Mission (SRTM) Digital Elevation Model (DEM) at $90 \mathrm{~m}$ spatial resolution.

- Sentinel-1A sigma-0 data $(15 \times 15 \mathrm{~m})$ during $20-30$ July 2017.

- Hydrometric data (river water level) from Central Water Commission (CWC) and Inland Waterways Authority of India (IWAI) for 2012, 2013 and 2017.

\section{Methodology}

\section{River water level}

Figure 2 shows the methodology adopted for river water level estimation. SIR backscatter data product of OSCAT satellite during 2010-13 was used to find pixel-level maximum and minimum backscattering coefficients and generate the maps. These gridded maps were utilized for the estimation of soil wetness index (SWI) using the change detection approach (eq. (1) $)^{20,21}$.

$$
\operatorname{SWI}(t)=\frac{\sigma^{0}(t)-\sigma_{\mathrm{dry}}^{0}}{\sigma_{\mathrm{wet}}^{0}-\sigma_{\mathrm{dry}}^{0}},
$$

where $\sigma^{0}(t)$ is the backscatter coefficient of a catchment pixel on a particular day, $\sigma_{\text {dry }}^{0}$ the minimum backscatter coefficient of the pixel, $\sigma_{\text {wet }}^{0}$ the maximum backscatter coefficient of the pixel and SWI is the soil wetness index. Here the time-series data are continuous, and exponential functions for SWI in its classical form are not necessary.

$$
\operatorname{BWI}(t)=\frac{\sum_{i}^{N} \operatorname{SWI}(t)}{N},
$$

where $N$ is the number of pixels in the upstream catchment of a gauging site.

Subsequently, wetness condition within the upstream catchment, which was delineated using SRTM DEM for a particular gauging site, was used to estimate BWI (eq. (2)). BWI values for each catchment were calibrated against ground-observed river stage data to develop model functions for different gauging sites. Inverting these functions on SCATSAT-1 observations provides river water levels for 2017.

\section{Surface inundation}

Microwave index, based on the microwave radiative transfer equation, was first proposed by Paloscia and Pampaloni $^{22}$. Many researchers have demonstrated the relationship between microwave polarization difference index (MPDI), and various soil and vegetation parameters. Singh et $a l^{23}$ used MPDI for monitoring of crop growth, whereas Owe et ll. $^{24}$ used it for retrieval of surface soil moisture. MPDI is defined as the normalized difference of BT in $V$ and $H$ polarizations at a given frequency. High-resolution BT data from SCATSAT-1 in $H$ and $V$ polarization have been used to compute MPDI over land pixels. Figure 3 summarizes the SCATSAT-1 flood detection algorithm.

$$
\mathrm{MPDI}=\frac{T_{b, v}-T_{b, h}}{T_{b, v}+T_{b, h}},
$$

where $T_{b, v}$ and $T_{b, h}$ are the brightness temperature in $V$ and $H$ polarization respectively. Li et $a .^{25}$ performed an analysis of MPDI over different land-cover types in northeast China for six AMSR-E frequencies. Since there are no spaceborne radiometers available at $13.6 \mathrm{GHz}$, the analysis by Li et $a .^{25}$ provides a good approximation of expected MPDI values over different land covers.

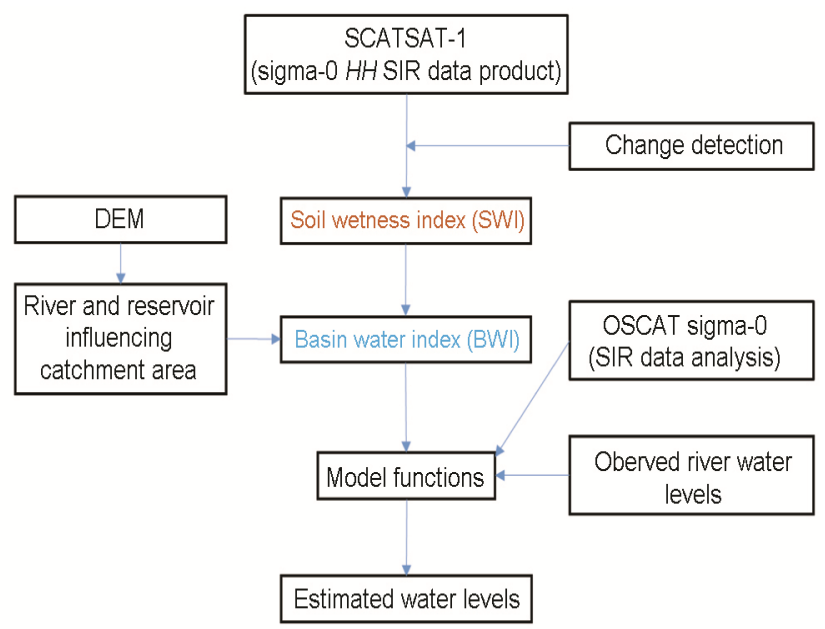

Figure 2. Flowchart of methodology for water-level estimation.

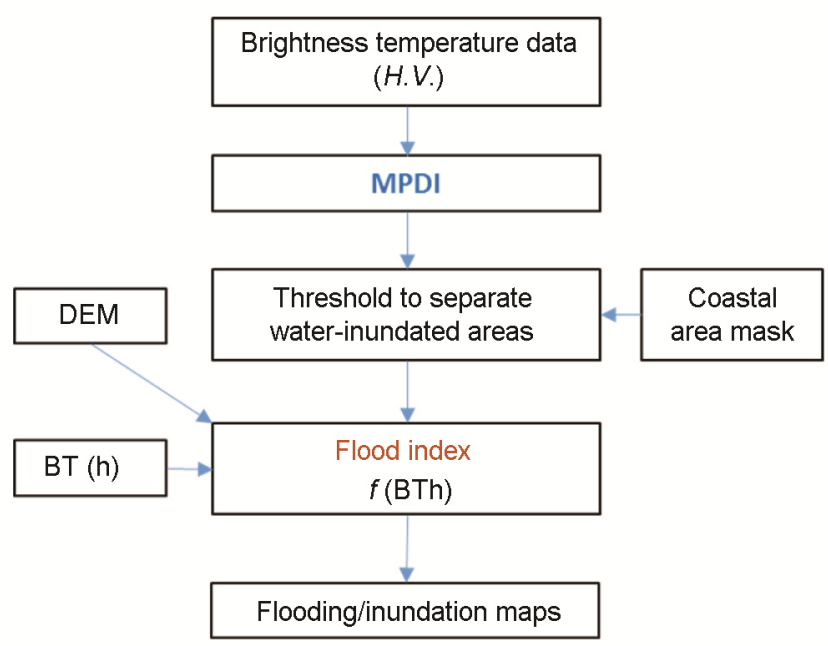

Figure 3. Flowchart of methodology for mapping of surface inundation. BT, Brightness temperature.

CURRENT SCIENCE, VOL. 117, NO. 6, 25 SEPTEMBER 2019 
Table 1. Locations, model coefficients and statistical parameters for different gauging sites

\begin{tabular}{|c|c|c|c|c|c|c|c|}
\hline \multirow[b]{2}{*}{ Site } & \multirow[b]{2}{*}{ Latitude $\left({ }^{\circ} \mathrm{N}\right)$} & \multirow[b]{2}{*}{ Longitude $\left({ }^{\circ} \mathrm{E}\right)$} & \multicolumn{3}{|c|}{ Model: $\mathrm{WL}=a(\mathrm{BWI})^{\mathrm{b}}+c$} & \multirow[b]{2}{*}{$R^{2}$} & \multirow[b]{2}{*}{ RMSE (m) } \\
\hline & & & $a$ & $b$ & $c$ & & \\
\hline Dhubri & 25.9164 & 89.9731 & 14.8978 & 1.7480 & 20.1800 & 0.85 & 0.84 \\
\hline Guwahati & 26.2291 & 91.3112 & 19.2373 & 2.2135 & 38.4751 & 0.85 & 1.03 \\
\hline Tezpur & 26.6110 & 92.7724 & 16.4821 & 2.2325 & 57.3598 & 0.81 & 0.98 \\
\hline Nematighat & 26.8654 & 93.9425 & 14.9303 & 2.9528 & 79.6410 & 0.85 & 0.64 \\
\hline Dibrugarh & 27.4687 & 94.8332 & 9.8878 & 3.1243 & 101.5246 & 0.81 & 0.42 \\
\hline Adityapor & 22.7863 & 86.1747 & 5.5945 & 2.9027 & 1.1222 & 0.53 & 0.77 \\
\hline Ghatsila & 22.5858 & 86.4617 & 7.1875 & 3.3987 & 1.7361 & 0.50 & 0.87 \\
\hline Tilga & 22.6439 & 84.4288 & 2.6082 & 2.9366 & 1.5380 & 0.45 & 0.41 \\
\hline Panposh & 22.2791 & 84.8522 & 6.3824 & 3.8866 & 0.5238 & 0.45 & 0.72 \\
\hline Gomali & 21.7946 & 84.9711 & 5.6828 & 2.1788 & 2.7841 & 0.56 & 0.74 \\
\hline Basantpur & 21.7222 & 82.7895 & 9.0570 & 3.4740 & 2.1138 & 0.62 & 0.82 \\
\hline Tikarapara & 20.6019 & 84.7761 & 31.6320 & 5.4913 & 4.4154 & 0.54 & 1.68 \\
\hline Kantamal & 20.6527 & 83.7234 & 5.9750 & 2.5730 & 1.4610 & 0.60 & 0.69 \\
\hline Purushottampur & 19.506 & 84.8718 & 2.3841 & 2.0463 & 0.2080 & 0.34 & 0.47 \\
\hline Kashinagar & 18.8503 & 83.871 & 2.3574 & 1.9011 & 1.8337 & 0.41 & 0.37 \\
\hline Hoshangabad & 22.7576 & 77.7325 & 11.6122 & 5.1423 & 2.3640 & 0.58 & 0.77 \\
\hline Mandleshwar & 22.1693 & 75.6597 & 9.6488 & 5.3692 & 2.4726 & 0.49 & 0.72 \\
\hline Burhanpur & 21.2996 & 76.2354 & 17.9434 & 7.1583 & 2.4803 & 0.66 & 0.83 \\
\hline Satrapur & 21.2301 & 79.2177 & 13.4456 & 7.1422 & 0.5994 & 0.64 & 0.58 \\
\hline PG Penganga & 19.8278 & 78.5733 & 14.9471 & 5.9308 & 1.0272 & 0.62 & 0.94 \\
\hline Pathagudem & 18.8485 & 80.348 & 27.4023 & 5.8825 & 0.4973 & 0.71 & 1.10 \\
\hline Mancherial & 18.8333 & 79.4484 & 2.3114 & 5.6034 & 1.0818 & 0.06 & 0.60 \\
\hline Polavaram & 17.2426 & 81.6488 & 23.2536 & 4.2530 & 2.2069 & 0.58 & 1.68 \\
\hline
\end{tabular}
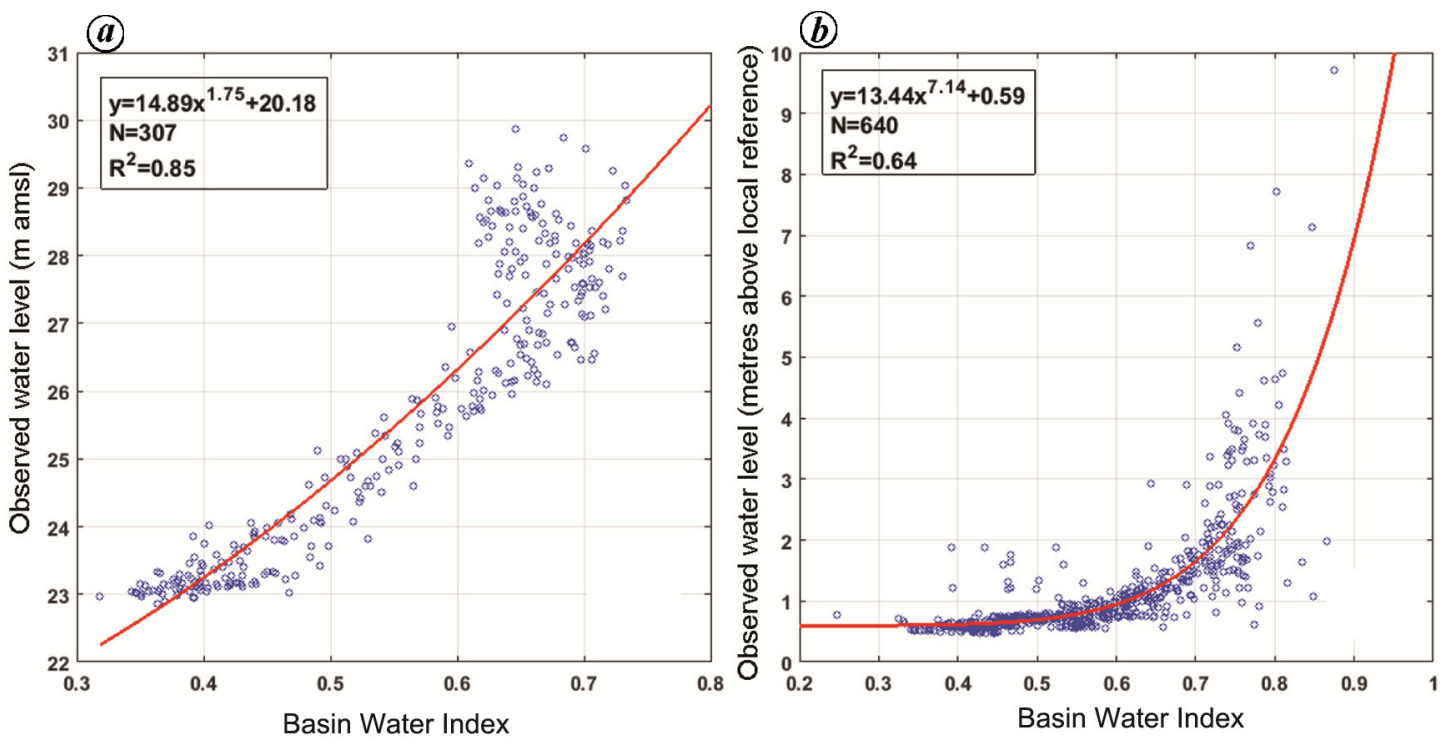

Figure 4. Model functions for two gauging sites: (a) Dhubri in the downstream of Brahmaputra river and (b) Satrapur in the upstream of Godavari river.

Regions with elevation greater than $1500 \mathrm{~m}$ were excluded from the analysis due to the effects of lowtemperature regions and rough surfaces on MPDI. Based on the analysis of Li et ll $^{25}$, an appropriate threshold of MPDI $>0.05$ was used to obtain inundated pixels. Along with this, BT values in $H$ polarization were used to further filter out the inundated pixels. Water has very low emissivity and reduces the brightness temperature. $\mathrm{BT}_{h}$ of the water-inundated regions ranged from approximately 160 to $240 \mathrm{~K}$. To determine the intensity of flooding within a detected pixel, a flood index was developed which uses a linear relation with $\mathrm{BT}$ in $H$ polarization, such that lower BT gives higher flood index. The range of flood index was set from 0 (no flooding) to 1 (completely flooded pixel). A coastal area mask of up to six pixels from the nearest coastline was applied due to contamination of 


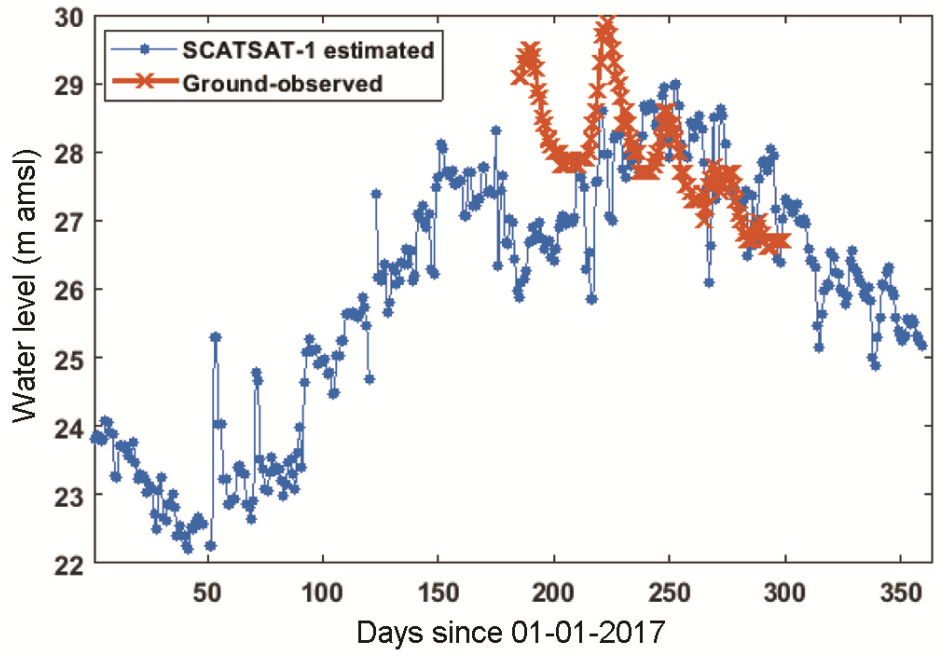

Figure 5. Observed versus estimated water levels for Dhubri site.
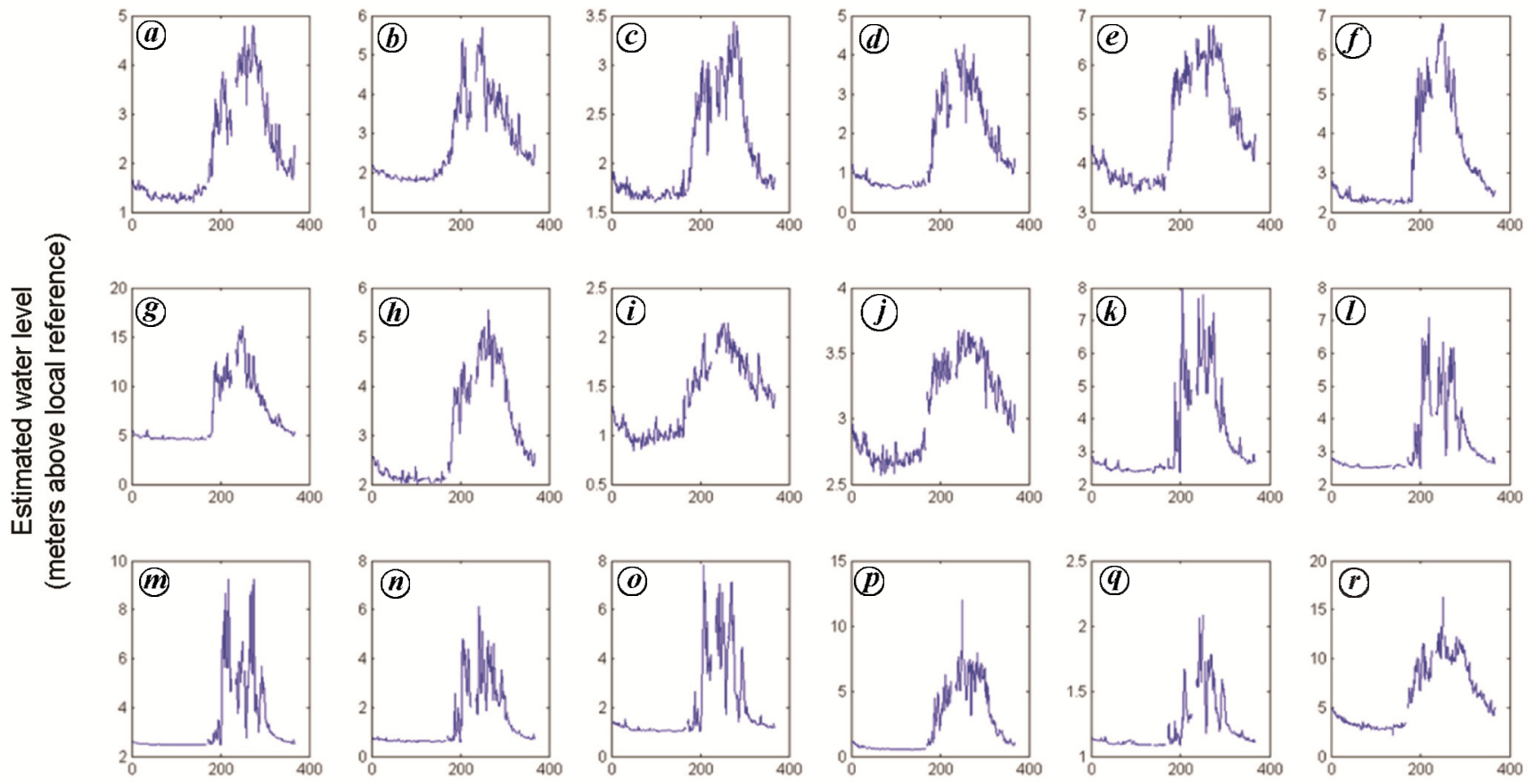

Days since 1 December 2016

Figure 6. Water level retrieved over 18 virtual gauging stations using SCATSAT-1 backscatter data (1 December 2016-22 December 2017). $\boldsymbol{a}$, Aditypor; $\boldsymbol{b}$, Ghatsila; $\boldsymbol{c}$, Tilga; $\boldsymbol{d}$, Panposh; $\boldsymbol{e}$, Gomali; $\boldsymbol{f}$, Basantpur; $\boldsymbol{g}$, Tikarapara; $\boldsymbol{h}$, Kantamal; $\boldsymbol{i}$, Purushottampur; $\boldsymbol{j}$, Kashinagar; $\boldsymbol{k}$, Hoshangabad; $\boldsymbol{l}$, Mandleshwar; $\boldsymbol{m}$, Burhanpur; $\boldsymbol{n}$, Satrapur; $\boldsymbol{o}$, PG Penganga; $\boldsymbol{p}$, Pathagudem; $\boldsymbol{q}$, Mancherial; $\boldsymbol{r}$, Polavaram.

high-resolution BT data by sea at coarse resolution. Flood conditions in Gujarat during 2017 were studied using SCATSAT-1 derived flood index maps. Sentinel-1A SAR data were used to identify surface inundation extent at high resolution and compared with the coarse resolution flood index maps.

An important characterization of floods in terms of the number of days of persistence of flooding conditions was studied for 2017. The number of days of water inundation was estimated based on the criterion with pixels having water fraction $>0.5$ (i.e. more than half the area of the pixel is inundated).

\section{Results}

\section{River water level}

The model functions were built on the relationship between satellite (OSCAT)-derived BWI and measured 
river water levels. The relationship between BWI and river water levels was observed to follow a power function $\left(y=a x^{b}+c\right)$. Figure 4 represents model functions for Satrapur (Godavari river) and Dhubri (Brahmaputra river) gauging sites. Similar model functions were developed for all the remaining sites shown in Figure 1. Table 1 presents the locations, model function coefficients, $R^{2}$ and RMSE values for all the gauging sites. These model functions were applied over the SCATSAT-1 dataderived basin water indices to estimate the river water levels for 2017 (Figures 5 and 6).

The model functions of BWI versus river water level show that run-off increases with increase in BWI, following a power law relation. This can be attributed to the fact

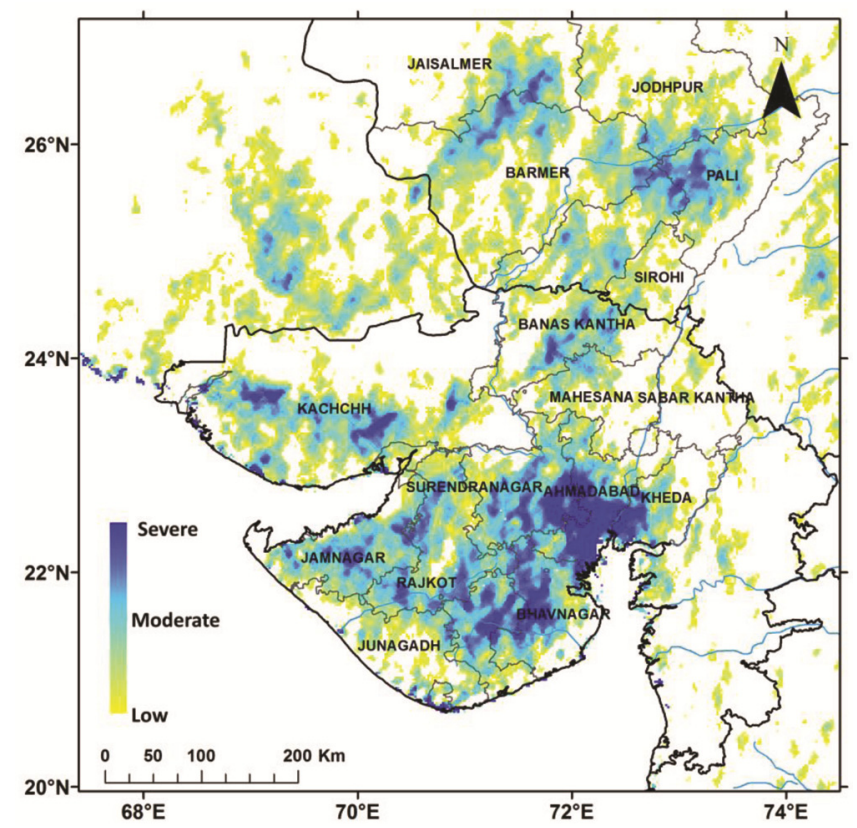

Figure 7. Surface inundation mapped over Gujarat during 22-26 July 2017 using SCATSAT-1 brightness temperature dataset.

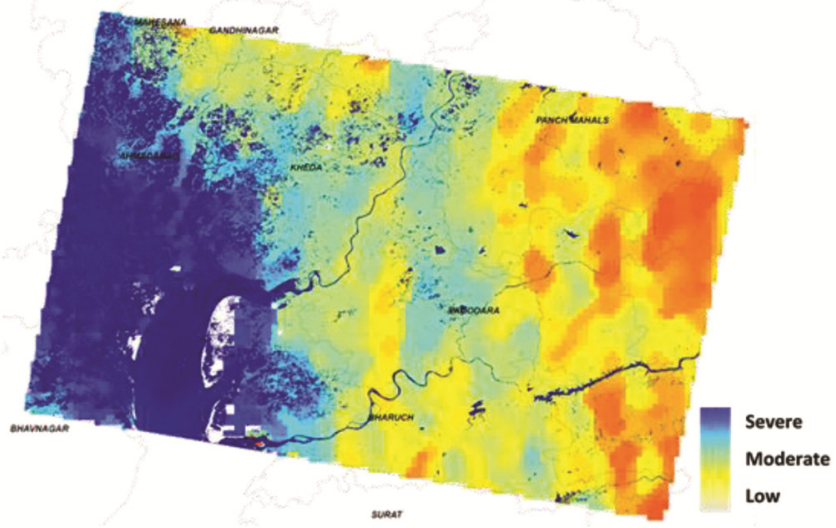

Figure 8. Inundation from SCATSAT-1 (Ku-band, coarse resolution) overlaid on flood pixels estimated from Sentinel-1A (C-band, high resolution) for 24 July 2017 in parts of Gujarat. that when the soil is dry, BWI is low and little run-off is being produced in response to rainfall (as more pore spaces are available to trap water in the soil). Run-off production increases sharply as BWI increases because of reduction in the infiltration capacity of the soil (as less number of pores is available). The steepness of curves depicting this relationship between BWI and river water level is taken as a measure of the storage capacity in the catchment, with very steep slopes indicating low storage capacity $^{14}$.

The model is found to be applicable in monitoring dry and wet season run-off for both types of catchment having low or high storage capacity with satisfactory levels ( $R^{2}$ ranging from 0.34 to 0.85 , and RMSE from $7 \%$ to $15 \%$ of total seasonal variation). A deviation from these results was observed for the Macherial site $\left(R^{2}=0.06\right)$ along Godavari river. This site is in the downstream of a nearby reservoir and hence, water levels are severely influenced by it. Brahmaputra being a natural system, with no man-made structures controlling the water flow, the correlation coefficients were maximum between BWI and observed water level for the five gauging sites along this river. However, this methodology has a limitation in estimating wet-season high flows, especially during high-flood wave conditions in flood-prone regions. In the case of Brahmaputra river, which experiences floods every year and parts of its floodplain get submerged with water, this deviation from model function is clearly observed.

During flood-wave conditions, some regions within the river's floodplains are inundated with water, which

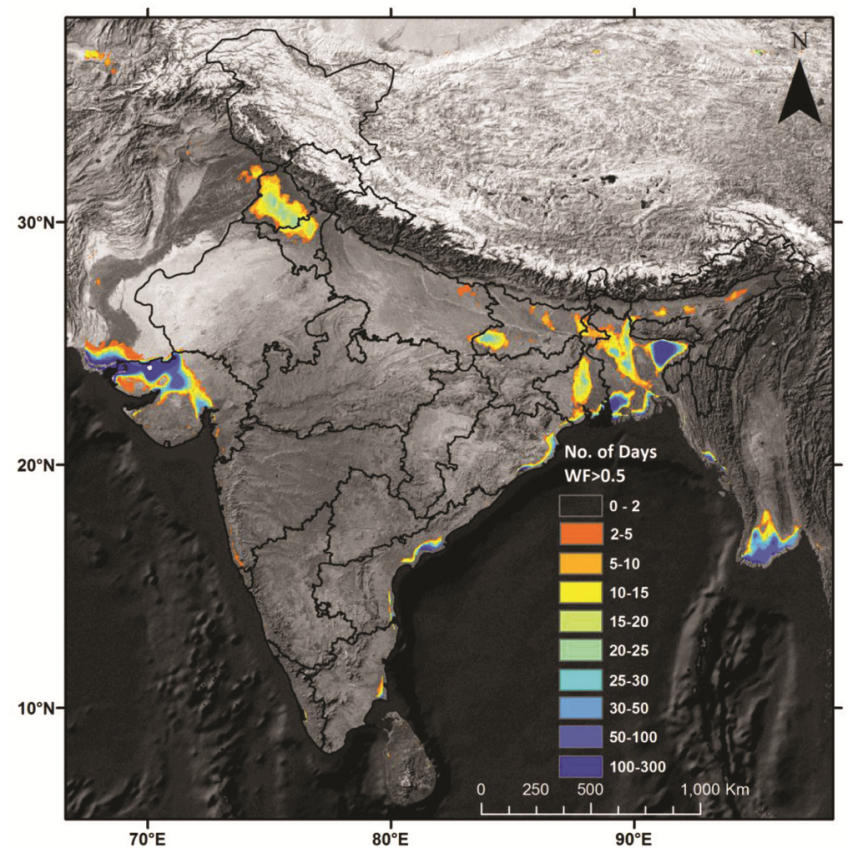

Figure 9. Flood extent and persistence map (water fraction greater than 0.5 ) over India and Bangladesh during 2017 using brightness temperature data from SCATSAT-1. 
reduces backscatter values of those pixels due to specular reflection of microwaves by the water surface. This reduces SWI value of the pixel and, when larger regions are inundated, also reduces BWI. As a result, the curve between BWI and observed water level (Figure $4 a$ ) loops back during high flow period causing significant difference between observed and estimated water levels. Figure 5 shows this difference for Dhubri site during June and July 2017. As water begins to recede, the BWI-water level relation follows the nominal curve. This is a major limitation of the current methodology and more work is needed to tackle this problem in future.

\section{Surface inundation}

Analysis of SCATSAT-1-derived BT data was used to identify the regions with various degrees of flooding (severe, moderate), or different soil wetness conditions. Extreme flooding conditions were observed in parts of Ahmedabad, Mehsana, Kheda, Banaskantha and Bhavnagar districts compared to relatively dry conditions in Bharuch and Surat regions of Gujarat during the fourth week of July (Figure 7). High-resolution data from Sentinel-1A, a C-band SAR imaging satellite, acquired on 24 July 2017 was used to compare the extent of inundated regions over parts of Gujarat. Observations of flooding conditions from SCATSAT-1 were well complemented by Sentinel-1A-derived inundation extent (Figure 8). It can be observed that regions with higher surface water extent in Sentinel-1A scene are represented with higher flood index values from SCATSAT-1. The proportion of inundated area within a coarser SCATSAT-1 pixel governs BT value and subsequently determines the flood index value, with higher values representing more flooding.

Time-series analysis of flood index, computed at daily intervals over India and the surrounding regions, was performed and persistence of flooding was computed. Figure 9 shows the flood persistence map over India and Bangladesh for 2017, which is the total number of days when water fraction was greater than 0.5 in that pixel.

In the map, regions of Punjab and Haryana show flooding well before the inception of rainfall due to inundation of the fields for rice cultivation in the region. Major flooding events of Kosi river in Bihar, Brahmaputra in Assam and regions of Bangladesh are identified very well. Water present in the Gulf of Kutch, Gujarat during monsoon season is also identified accurately in the flood maps. However, partial inundation within a pixel results in lower flood index values. Flood index may be affected by the inherent errors in the determination of BT.

\section{Conclusion}

In this study, we proposed a methodology for estimation of river water level and detection of surface inundation using SCATSAT-1 backscattering coefficient and BT datasets respectively. We demonstrate the capability of SCATSAT-1 to estimate river water levels utilizing satellite-measured soil wetness conditions through the process of run-off at the catchment scale. Natural river systems showed highest correlation (Brahmaputra gauging sites), whereas poor correlation was observed for river systems which were heavily controlled by man-made structures. Another application of the scatterometer for detection of surface flooding was demonstrated for monitoring largescale floods. It can also be helpful in assessing the magnitude of each flooding event in terms of intensity, duration and extent of area affected. Analysis of selected gauging site data showed the usefulness of SCATSAT-1 mission for land hydrological applications such as soil moisture, river hydraulics, flood hazards, etc. with high temporal resolution. More details can be obtained from the VYOM (www.sac.gov.in/Vyom/index.jsp/) and VEDAS (http:// vedas.sac.gov.in/vedas/) web portals of Space Applications Centre (SAC, (ISRO)), Ahmedabad. Further studies are required to address the under-prediction of water level during extreme flood conditions by combining scatterometer and passive microwave radiometer observations.

1. Kumar, R. et al., Evaluation of Oceansat-2-derived Ocean surface winds using observations from global buoys and other scatterometers. IEEE Trans. Geosci. Remote Sensing, 2013, 51(5), 25712576.

2. Naeimi, V., Leinenkugel, P., Sabel, D., Wagner, W., Apel, H. and Kuenzer, C., Evaluation of soil moisture retrieval from the ERS and MetOp scatterometers in the Lower Mekong basin. Remote Sensing, 2013, 5, 1603-1623.

3. Cui, Y. et al., Estimating snow water equivalent with backscattering at $\mathrm{X}$ and $\mathrm{Ku}$ band based on absorption loss. Remote Sensing, 2016, 8, doi:10.3390/rs8060505.

4. Turk, F. J., Sikhakolli, R., Kirstetter, P. and Durden, S. L., Exploiting over-land Oceansat-II scatterometer observations to capture short-period time-integrated precipitation. J. Hydrometeorol., 2015, 16, 2519-2535.

5. Remund, Q. P. and Long, D. G., Sea ice extent mapping using Ku-band scatterometer data. J. Geophys. Res.: Oceans, 1999, 104(C5), 11515-11527.

6. Ulaby, F. T., Moore, R. K. and Fung, A. K., In Microwave Remote Sensing, Fundamanetals and Radiometery, Vol. 1, Deedham MA, Artech House, 1981.

7. Ulaby, F. T., Moore, R. K. and Fung, A. K., In Microwave Remote Sensing, from Theory to Applications, Vol. 3, Deedham MA, Artech House, 1986.

8. Fung, A. K., In Microwave Scattering and Emission Models and their Applications, Norward MA, Artec House, 1994.

9. Misra, T. et al., Oceansat-II scatterometer: sensor performance evaluation, $\sigma^{0}$ analyses and estimation of biases. IEEE Trans. Geosci. Remote Sensing, 2014, 52(6), 3310-3315.

10. Ulaby F.T., Batlivala, P. P. and Dobson, M. C., Microwave backscatter dependence on surface roughness, soil moisture and soil texture, Part-I: bare soil. IEEE Trans. Geosci. Electron., 1978, GE-16, 286-295.

11. Birkett, C. M., Mertes, L. A. K., Dunne, T., Costa, M. H. and Jasinski, M. J., Surface water dynamics in the Amazon Basin: application of satellite radar altimetry. J. Geophys. Res., 2002, 107, LBA 26. 
12. Brakenridge, G. R., Tracy, B. T. and Knox, J. C., Orbital remote sensing of a river flood wave. Int. J. Remote Sensing, 1998, 19, 1439-1445.

13. Townsend, P. A. and Foster, J. R., Assessing flooding and vegetation structure in forested wetlands using Radarsat SAR imagery. In IEEE International Geoscience Remote Sensing Symposium, IGARSS, Toronto, Canada, 2002, vol. 2, pp. 1171-1173.

14. Scipal, K., Scheffler, C. and Wagner, W., Soil moisture-runoff relation at the catchment scale as observed with coarse resolution microwave remote sensing. Hydrol. Earth Syst. Sci., 2005, 9, 173-183.

15. De Jeu, R., Wagner, W., Holmes, T. R. H., Dolman, A. J., Van De Giesen, N. C. and Friesen, J., Global soil moisture patterns observed by space borne microwave radiometers and scatterometers. Surv. Geophys., 2008, 29(4-5), 399-420.

16. Hirpa, F. A., Gebremichael, M. and Over, T. M., River flow fluctuation analysis: effect of watershed area. Water Resour. Res. 2010, 46, W12529.

17. Brakenridge, G. R., Knox, J. C., Magilligan, F. J. and Paylor, E., Radar remote sensing aids study of the Great flood of 1993. EOS, Trans. Am. Geophys. Union, 1994, 75(45), 521-528.

18. Gstaiger, V., Huth, J., Gebhardt, S., Wehrmann, T. and Kuenzer, C., Multi-sensoral and automated derivation of inundated areas using TerraSAR-X and ENVISAT-ASAR data. Int. $J$ Remote Sensing, 2012, 33(22), 7291-7304.

19. Brakenridge, G. R., Anderson, E., Nghiem, S. V., Caquard, S. and Shabaneh, T. B., Flood warnings, flood disaster assessments and flood hazard reduction: the roles of orbital remote sensing. In Proceedings of 30th International Symposium on Remote Sensing of the Environment, Honolulu, Hawaii, 2002, p. 4.

20. Wagner, W., Noll, J., Borgeaud, M. and Rott, H., Monitoring soil moisture over the Canadian prairies with the ERS scatterometer. IEEE Trans. Geosci. Remote Sensing, 1999, 37, 206-216.
21. Moran, M. S., Hymer, D. C., Qi, J. and Sano, E. E., Soil moisture evaluation using multi-temporal synthetic aperture radar (SAR) in Semiarid Rangeland. Agric. For. Meteorol., 2000, 105, 69-80.

22. Paloscia, S. and Pampaloni, P., Experiment relationships between microwave emission and vegetation features. Int. J. Remote Sensing, 1985, 6, 315-323.

23. Singh, R. P. and Dadhwal, V. K., Comparison of space-based microwave polarization difference index and normalized difference vegetation index for crop growth monitoring. Indian J. Radio Space Phys., 2003, 32, 193-197.

24. Owe, M., de Jen, R. and Walker, J., Vegetation optical depth retrieval using the MPDI. IEEE Trans. Geosci. Remote Sensing, 2001, 39(8), 1643-1654.

25. Li, Y., Zhao, K., Zheng, X. and Ren, J., Analysis of microwave polarization difference index characteristics about different vegetation types in northeast of China. In International Conference on Remote Sensing, Environment and Transportation Engineering, Nanjing, China, 2013; doi:10.2991/rsete.2013.9.

ACKNOWLEDGEMENTS. We thank Shri D. K. Das (Director, SAC (ISRO), Ahmedabad), Dr Raj Kumar (Deputy Director, EPSA, SAC) and Dr A. S. Rajawat (Group Director, Geo-Sciences, Hydrosphere, Cryosphere Sciences and Applications Group, EPSA, SAC) for motivation, guidance and support. We also thank Nimisha Singh (Land Hydrology Division, EPSA, SAC) for help with data processing and map generation; CWC and IWAI for providing the hydrometric datasets for analysis, and European Space Agency for Sentinel-1A data.

doi: $10.18520 / \mathrm{cs} / \mathrm{v} 117 / \mathrm{i} 6 / 1014-1021$ 